\title{
Article \\ Outcomes of Ceramic Composite in Total Hip Replacement Bearings: A Single-Center Series
}

\author{
Giuseppe Solarino *, Antonio Spinarelli, Antonio Virgilio *, Filippo Simone, Marco Baglioni and Biagio Moretti
}

Citation: Solarino, G.; Spinarelli, A.; Virgilio, A.; Simone, F.; Baglioni, M.; Moretti, B. Outcomes of Ceramic Composite in Total Hip Replacement Bearings: A Single-Center Series. J. Compos. Sci. 2021, 5, 320. https://doi.org/10.3390/jcs5120320

Academic Editor:

Francesco Tornabene

Received: 25 October 2021

Accepted: 6 December 2021

Published: 8 December 2021

Publisher's Note: MDPI stays neutral with regard to jurisdictional claims in published maps and institutional affiliations.

Copyright: (c) 2021 by the authors. Licensee MDPI, Basel, Switzerland. This article is an open access article distributed under the terms and conditions of the Creative Commons Attribution (CC BY) license (https:/ / creativecommons.org/licenses/by/ $4.0 /)$.
Department of Basic Medical Sciences, Neuroscience and Organs of Sense, School of Medicine, AOU Policlinico Consorziale, Università di Bari "Aldo Moro", 70124 Bari, Italy; antonio.spinarelli@gmail.com (A.S.); filsimo1993991@gmail.com (F.S.); baglioni.m86@gmail.com (M.B.); biagio.moretti@uniba.it (B.M.)

* Correspondence: giuseppe.solarino@uniba.it (G.S.); antoniovirg@yahoo.it (A.V.);

\begin{abstract}
Despite the fact that total hip replacement is one of the most successful surgical procedures for treatment of a variety of end-stage hip diseases, the process of osteolysis and implant loosening remains a significant problem, especially in young and high-demand patients. More than 40 years ago, ceramic bearings were introduced due to their mechanical advantage in order to obtain a reduction in wear debris, and due to the conviction that it was possible to minimize friction and wear owing to their mechanical hardness, high chemical stability, surface lubrication by fluids and low friction coefficient. Together with excellent mechanical properties, ceramics have a biological inertness: eventual ceramic debris will lead to a reactive response with a high predominance of fibrocystic cells, rather than macrophagic cells, and absence of giant cells, which is ideal from a biological perspective. As a consequence, they will not trigger the granulomatous reaction necessary to induce periprosthetic osteolysis, and this clearly appears to be of great clinical relevance. In recent years, tribology in manufacturing ceramic components has progressed with significant improvements, owing to the development of the latest generation of ceramic composites that allow for an increased material density and reduced grain size. Currently, ceramic-on-ceramic bearings are considered the attractive counterparts of ceramic- or metal-on-polyethylene ones for patients with a long life expectancy. The aim of this paper is to report the results of total hip replacements performed with a ceramic-on-ceramic articulation made from a ceramic composite in a single center, focusing on its usefulness in specific preoperative diagnosis.
\end{abstract}

Keywords: hip; alumina matrix composite; AMC; hip prosthesis; prosthesis; case series; ceramic-on-ceramic

\section{Introduction}

Currently, one of the most successful operations in the orthopedic surgery field is prosthetic hip replacement (total hip arthroplasty, THA), owing to the excellent immediate results, and in the long term, it is possible to obtain a rapid recovery with great satisfaction from patients.

Over the years, there has been continuous research in order to obtain an improvement in the components of prostheses in order to reduce complications and maximize results.

From a tribological point of view, there has been a continuous development of materials and a continuous search for the best combinations of materials, especially in terms of duration and complications. The choice of materials is, in fact, able to influence the functional recovery, to reduce the risk of complications including the formation of debris and to reduce the number of revisions, thus influencing the long-term duration of prostheses.

In 1962, the introduction of ultra-high molecular weight (UHMW) polyethylene as a bearing material by Sir John Charnley was the first important push toward the modern THA procedure. Some years later, in 1971, Pierre Boutin introduced the ceramic alumina as a coupling in hip implants, realizing the alumina-on-alumina THA procedure [1]. 
Among the various characteristics of alumina, there is its hydrophilic property which therefore allows for excellent lubrication of prostheses [2].

Subsequently, over the years, there has been a continuous evolution of ceramics, owing to the progressive reduction in the dimensions of particles that compose them, and hot pressurization techniques, resulting in a progressive increase in flexural resistance. Several generations of alumina have followed one another, of which the third generation of ceramics is called BIOLOX ${ }^{\circledR}$ forte [3].

The most important improvement was obtained through the creation of the alumina matrix composite $(\mathrm{AMC})$, obtained by joining alumina $(82 \%)$ to zirconia oxide, strontium aluminate and chromium oxide particles; in this way, the density of the material and its three-dimensional composition can be modified, obtaining a much harder and more resistant compound. This material is the fourth generation of alumina and is called BIOLOX $^{\circledR}$ delta [4]. Important features of the AMC are its resistance in the event of impacts and malpositioning and, above all, the possibility to use large-diameter heads while maintaining a very thin insert, in order to ensure maximum mobility and minimize the risk of dislocation [5]. Among the advantages of using the alumina matrix composite (AMC), there is the low frequency of complications [6-8]. Osteolysis related to wear debris is one of the major reasons for failure of hip prostheses and is therefore capable of negatively affecting the survival of THA implants, especially in young patients [9-12]. Although there is a risk of osteolysis, this occurrence is still very rare. Kim et al. in 2016, in the case of implants with a delta ceramic head and polyethylene liner (HXLPE), did not detect any case of osteolysis in patients under 50 years and with an average follow-up of 11.9 years [13]. Depending on the used materials, the possible complications related to debris are variable. In the case of use of metal-on-metal prostheses, there is an excretion of ions in the urine, toxicity, neuropathies and the possibility of developing a pseudotumor. The ceramic-onceramic $(\mathrm{CoC})$ combination is able to guarantee optimal tribological properties including exceptional hardness, excellent wettability and lubrication and, above all, a very low release of particles, which, in any case, have a high level of biocompatibility [14,15]. It should also be considered that over the course of various generations of ceramics, the risk of ceramic fracture associated with this material has enormously decreased, owing to improvements from the point of view of design and manufacturing processes, and it should stand at values between $0.001 \%$ and $0.021 \%$ [16]. According to a 2017 evaluation, new composite ceramics have lowered the risk of femoral head fracture to $0.002 \%$; however, the risk of liner fracture has increased somewhat $(0.02 \%)$. Ceramic bearings provide substantial advantages over traditional bearings, according to the authors, given that the components are introduced without impingement [17]. Howard et al. used data from the National Joint Registry (NJR) for England, Wales, Northern Ireland and the Isle of Man to show that there is good evidence that the latest generation of ceramic has greatly reduced the risk of head fracture, and that a small head size and a high patient BMI are associated with an increased risk of ceramic bearing fracture [18]. Yoon et al. performed a meta-analysis on 10,571 THAs from 45 trials and found that the AMC performed better than third-generation ceramic components [19].

Buttaro et al. retrospectively reviewed 939 cases (880 patients) of primary total hip arthroplasty with fourth-generation delta ceramic-on-ceramic bearings and found that the mean survival rate was $99.3 \%$ at $2-10$ years, when revision or impending revision in relation to the bearing surface was considered the end point. They emphasized that the few problems they discovered were due to technical mistakes that surgeons should avoid when utilizing this type of surface [20]. According to Lee et al., who analyzed 2.78 million AMC ceramic ball heads implanted globally, the incidence of clinical fractures of contemporary AMC femoral heads is 1 in 100,000 (0.0010\%). The majority of implant failures happened within 48 months after surgery, and they were typically caused by particular events such as trauma, mismatched components and dislocations [21]. Ceramics have a biological inertness: fibrocystic cells-rather than giant and macrophagic cells-are involved with high predominance in response as a reaction to eventual ceramic particles being worn out, 
which will lead to an ideal response from a biological perspective; in fact, an undesired consequence, i.e., periprosthetic osteolysis due to a granulomatous reaction, will not be induced and this obviously has enormous clinical relevance [22,23].

\section{Our Experience}

We looked at 62 cementless AMC-on-AMC THAs conducted on 54 patients in a row. Patients were operated on bilaterally in eight cases, with THAs performed on separate dates. We received clearance from our hospital's review board, and 32 men and 22 women, ranging in age from 14 to 68 , were recruited in this retrospective study. In 34 cases, the right hip was operated on, while the left was operated on in 28 cases. Diagnoses were as follows: osteoarthritis, either primary or secondary, was diagnosed in 32 cases $(51.6 \%)$, avascular necrosis of the femoral head in 12 cases (19.35\%), intracapsular displaced fracture of the femoral neck in 12 cases (19.35\%), secondary osteoarthritis as a sequela of Legg-CalvePerthes disease/developmental congenital dysplasia of the hip/slipped capital femoral epiphysis in 4 cases $(6.45 \%)$ and rheumatic arthritis in two cases (3.22\%). Two fellowshiptrained orthopedic surgeons performed preoperative templating to determine the right size of the components. All of the procedures were conducted by senior registrars with expertise in joint arthroplasty surgery; no orthopedic trainee, even under supervision, was ever engaged as the initial surgeon in any THA. All of the THAs were primary operations that were implanted in a traditional turbulent flow theater utilizing a direct lateral approach. After the acetabulum was reamed, the acetabular cup was set with a desired inclination angle of $40-45^{\circ}$ and a planned anteversion of $15-20^{\circ}$. Only cementless hemispherical cups were implanted, and their outer diameter was as follows: 54 in 16 cases $(26.6 \%), 50$ in $12(20 \%), 52$ in $8(13,3 \%), 56$ in $8(13.3 \%), 58$ in $6(10 \%), 60$ in $4(6.6 \%), 46$ in $4(6.6 \%), 48$ in $2(3.22 \%)$ and 62 in $2(3.22 \%)$. Additional acetabular screws were utilized to complete fixation based on the patient's bone quality and the surgeon's choice, but there was no apparent link to the preoperative diagnosis. Before the ceramic inlay can be placed and positioned, the metal shell must be clean and dry on the inside. Because they cannot be crushed, every little piece of soft or bone tissue, any fluid and any remnant of cement must be removed from the metal shell. It is critical to confirm that the right seat of the ceramic insert has been attained by touching the cup rim with the fingers: the ceramic and metal rims must lay flat to one another. The biggest broach that would fill the metaphysis and leave minimal cancellous bone left was utilized to implant all cementless femoral components using a press fit method. Thorough cleaning and drying of the taper on the stem side are also required because any foreign material reduces the fracture strength of the ceramic femoral ball head and impairs its force transmission. Because relative motions between the components are minimized, a slight rotating motion when placing the ceramic head will ensure a safe locking. Finally, ensuring the femoral ball head is placed securely requires a moderate hammer blow on the impactor in the axial direction of the stem taper. The shuck test and examination of the main arc range of motion were used to examine the stability of the hip implant before it was closed in layers. The diameter of the femoral head utilized was at the discretion of the surgeon: a $36 \mathrm{~mm}$ femoral head was implanted in 44 hips (70.96\%), a $32 \mathrm{~mm}$ femoral head in 14 hips (22.5\%) and a $40 \mathrm{~mm}$ femoral head in 4 cases $(6.45 \%)$. All patients received the same perioperative care: antibiotic and thromboembolic prophylaxis with heparin administration and compression stockings, passive motion exercises with a therapist immediately after the operation, removal of the single intraarticular suction drain on the second postoperative day and patients free to walk with two supports after three days for about six weeks. Preoperatively and postoperatively, patients were assessed at 6 weeks, 3 months, 1 year and every 2 years thereafter. Clinically, a history of squeaking and all postoperative problems were noted at each visit, and patient activity was measured using the Harris Hip Score (HHS); the preoperative HHS averaged 36.7 (range 15-58). The same observer who had not been engaged in the procedures for tilting or migration of the cup, radiolucent lines and osteolysis in acetabular component zones acquired and examined an anteroposterior pelvic and axial view of the affected hip 
radiographically. A cup migration of more than $3 \mathrm{~mm}$, an angular rotation of more than $3^{\circ}$ and/or a continuous radiolucent line wider than $2 \mathrm{~mm}$ were all considered loosening. Around the femoral component, there were indications of stem subsidence or displacement, as well as osteolysis. Our cutoff for vertical migration was set at $3 \mathrm{~mm}$, and osteolysis was defined as a sharply demarcated lucent area adjacent to the acetabular and/or femoral component that was not visible on the immediate postoperative radiographs. All local problems, such as periprosthetic infection, dislocation, intraoperative and postoperative periprosthetic fracture and liner and/or head breakages, were documented.

Due to the death or loss of two patients with two THAs at the last follow-up at the study census date, 60 THAs were eligible for the current study. The mean HHS increased to 92.1 points (range 61-100) among them, with no significant differences between groups in terms of the preoperative diagnosis that led to the procedure. None of the implants' components failed due to mechanical failure, and none of them dislocated. The patients never mentioned squeaking.

\section{Discussion}

\subsection{AMC-on-AMC Total Hip Replacement in Avascular Necrosis of the Femoral Head}

Avascular necrosis (AVN) or osteonecrosis of the femoral head is caused by a lack of blood supply in the region; in the later stages of the disease, bone is reabsorbed and the epiphysis collapses: it is obvious that hip replacement with THA, which provides immediate pain relief and excellent functional outcomes, should be considered the preferred treatment. Nevertheless, previous reports have underlined that avascular necrosis represents a risk factor of biomechanical failure of implants [24,25] due to the pathogenesis of periprosthetic osteolysis, strictly connected to wear debris of polyethylene. Such a cause of failure of a THA remains one of the most prevalent in young and active patients, and thus alternative hard materials have been developed as bearing surfaces in clinical practice to reduce the detrimental effects of wear on prosthesis survival. As a result, there has been a revived interest in hard components as surfaces for total joint arthroplasty, including ceramicon-ceramic and metal-on-metal bearings. However, despite their remarkable tribological characteristics (friction, lubrication and wear), specific difficulties must be accounted for with such materials because metallic ions or ceramic particles may be generated; furthermore, the biologic cascade resulting from debris created by these alternative bearings has yet to be completely understood. Current metal-on-metal bearings are self-polishing and made of cobalt-chromium-molybdenum alloys with varying carbon contents; undoubtedly, debris from such bearings is to blame for increased metal ion levels in urine and blood, eventual toxicity, capsular aggregation of lymphocytes and pseudotumor growth, all of which can cause neuropathy and delayed-type hypersensitivity. Park et al. [26] have already demonstrated a hypersensitivity reaction to cobalt in patients with early osteolysis after contemporary metal-on-metal THAs using skin patch tests, whereas Savarino et al. [15] have demonstrated high levels of cobalt and chromium with metal-on-metal articulations and negligible serum metal ion contents in ceramic-on-ceramic THAs using skin patch tests; they concluded that, because of the increased ion release, metal-on-metal coupling should be used with caution, particularly in young patients. We feel that when THAs are conducted in patients with AVN, certain critical precautions should be taken into account because this condition is considered a risk factor. According to Ortiguera et al. [27], the dislocation rate in osteonecrosis patients is expected to be much higher than in osteoarthritic patients because subjects with AVN have potentially much less stiffness than patients with osteoarthritis and thus are able to achieve a wider range of hip movement after surgery, making them more prone to joint instability. Berry et al. [28] examined the cumulative incidence of dislocation in a cohort of over 6000 prosthetic hips and found it to be more than doubled ( $14.1 \%$ compared to $6.4 \%$ ) in patients with osteonecrosis than in those with osteoarthritis; their research also found that dislocation rates rise with extended durations of follow-up, possibly reflecting the impact of neuromuscular degeneration and, in particular, wear at the metal-on-polyethylene articulating surface. 
Ceramic hip arthroplasty, we feel, is the most reliable treatment to suggest in active, youthful patients with a long life expectancy, such as those with AVN. Wear is often higher in this demographic. Intracellular ceramic wear debris, which may be observed in the soft periarticular tissues, will create an inflammatory reaction that the organism will tolerate much better than the one caused by metal-on-metal articulation, and as a result, it will be less aggressive. Ceramics have excellent biocompatibility due to their favorable tribologic properties, biologic inertness, extremely good surface finish and unique hardness, which allows surgeons to use femoral heads with diameters greater than $28 \mathrm{~mm}$ while also providing an increased range of motion and decreased dislocation, as well as a very low friction coefficient and high wear resistance.

Furthermore, other authors [29] comparing 654 THAs conducted for AVN and performed in 327 patients with an average age of 42 years operated bilaterally, with a CoC THA on one side and a CoPE THA on the contralateral side, demonstrated that the risk of a femoral fracture around the stem was strictly related to the bearing components used during prosthetic implantation. They discovered that late postoperative periprosthetic fractures increased in quantity with follow-up and occurred 30 times more commonly on the side with the PE cup than on the side with the $\mathrm{CoC}$ bearing. They came to the conclusion that because of the lack of wear and osteolysis, $\mathrm{CoC}$ couples reduce the incidence of late periprosthetic fractures.

In Figure 1, the case of the youngest patient in our group is shown: a 14-year-old girl suffering for multifocal AVN due to treatment for acute lymphoblastic leukemia. She was complaining of severe pain and considerable functional impairment in her left hip: a $48 \mathrm{~mm}$ cup with $32 \mathrm{~mm}$ AMC-AMC bearings on a standard stem was used.

\subsection{Alumina-on-Alumina Total Hip Replacement in Developmental Dysplasia of the Hip}

THA in sequelae of developmental dysplasia of the hip (DDH) is a challenging and difficult procedure in terms of restoring the normal biomechanics. In case of dysplastic patients, the pre- and intraoperative process of decision making is also complex due to the underdeveloped acetabulum, the contracture of the surrounding soft tissues and often the high riding head; on the pelvic side, the choice is frequently linked to the need of using small-diameter acetabular cups because DDH causes a lack of bone under the prosthesis, and sometimes, it may not be possible to place a large acetabular cup in the anatomical position with a medialization close to the radiological tear drop because of the hypoplasic acetabulum and thus the risk of miscoverage of the shell (Figure 2). We are convinced that obtaining the correct location of the acetabular cup, and thus providing the best function of the artificial hip, is dependent on the outer diameter of the shell because, typically, a cup with a small diameter is used, and as a result, the thickness of the acetabular insert decreases, the two components being inextricably linked. We are aware of manufacturer information stating that a $32 \mathrm{~mm}$ HXLPE inlay may only be utilized with a cup diameter of $52 \mathrm{~mm}$ or more [30]. The presence of small-diameter cups affects the size of the insert which will be proportionally smaller. The use of the AMC in these patients is essential because it allows the combination of very thin inserts even in acetabular cups with a reduced diameter, combining them with large diameter heads [31]. Inadequate polyethylene thickness is identified as the source of plastic particle-mediated osteolysis, not only in conventional polyethylene [32] but also in vitamin E-diffused HXLPE, and hence significant liner thinning is not advised [33]: Higher peak contact loads and smaller contact areas result from a decrease in polyethylene liner thickness or headliner conformance, resulting in reduced biomechanical wear factors. On the other hand, since larger femoral heads have been widely advocated to improve implant stability and range of motion, especially in patients with spinopelvic alignment, such as patients with hip osteoarthritis secondary to $\mathrm{DDH}$, prosthetic heads must be enlarged, implying a reduction in liner thickness [34-40]. 


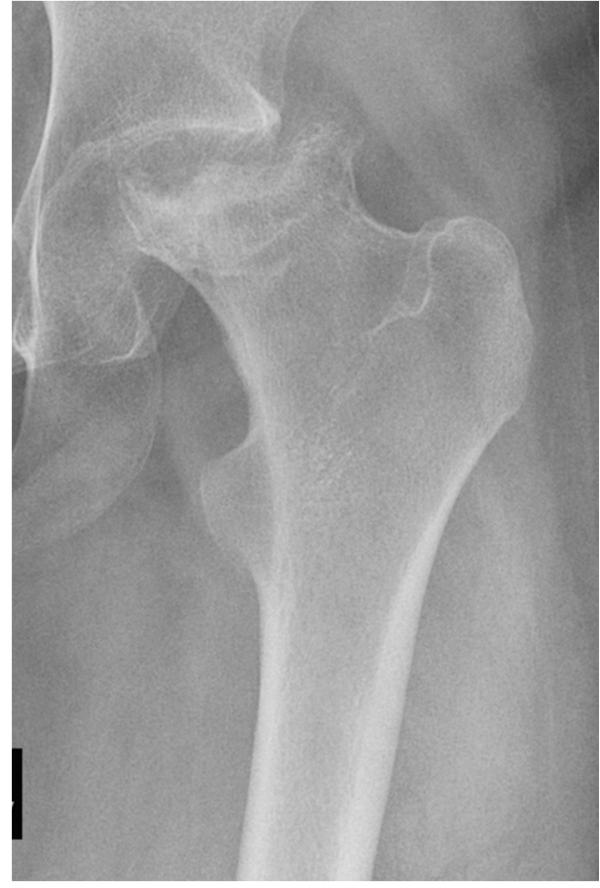

(a)

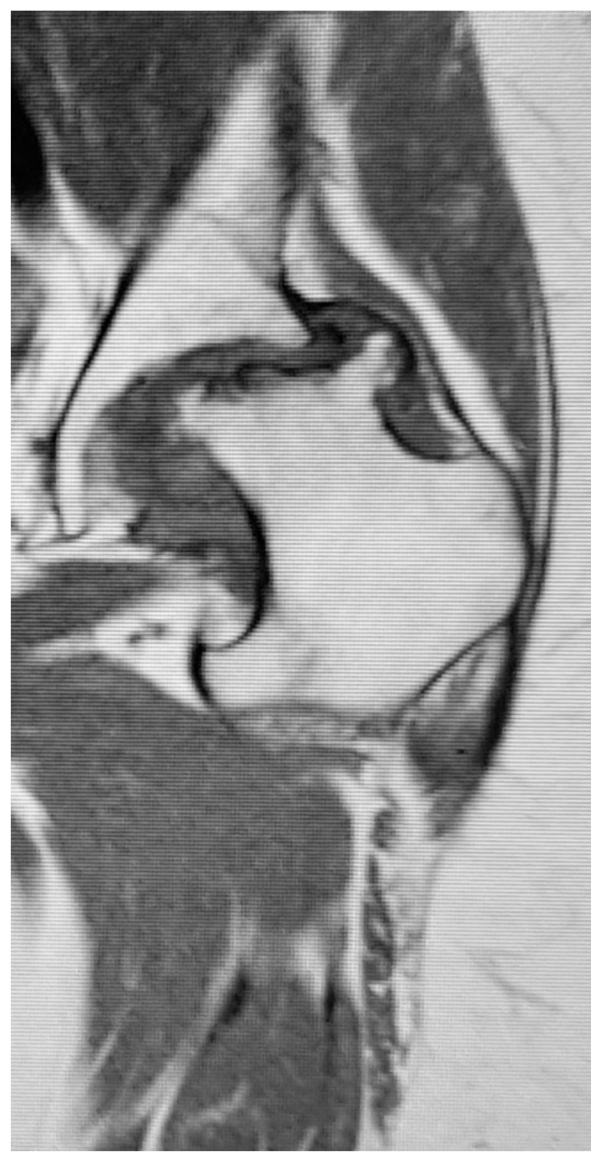

(c)

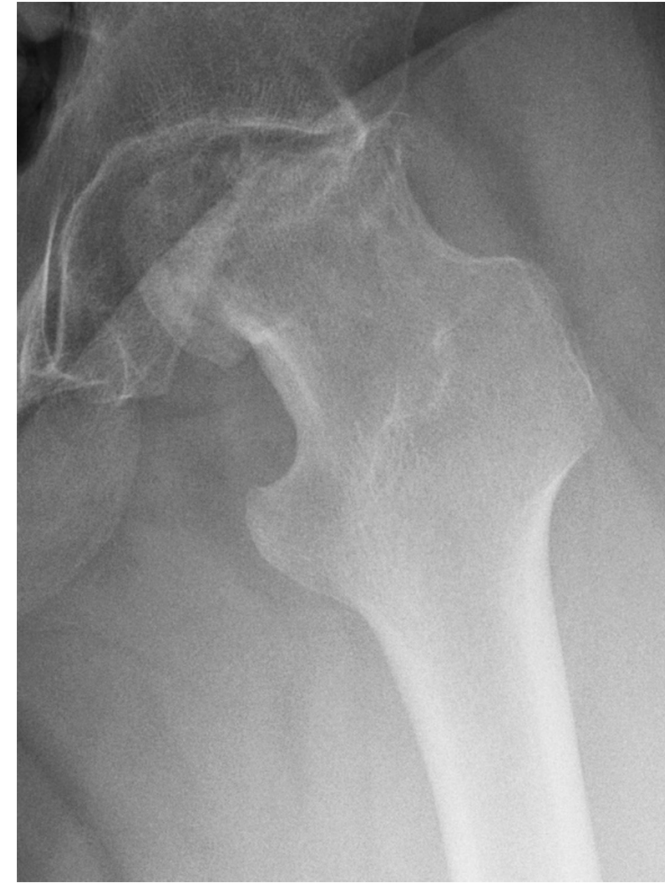

(b)

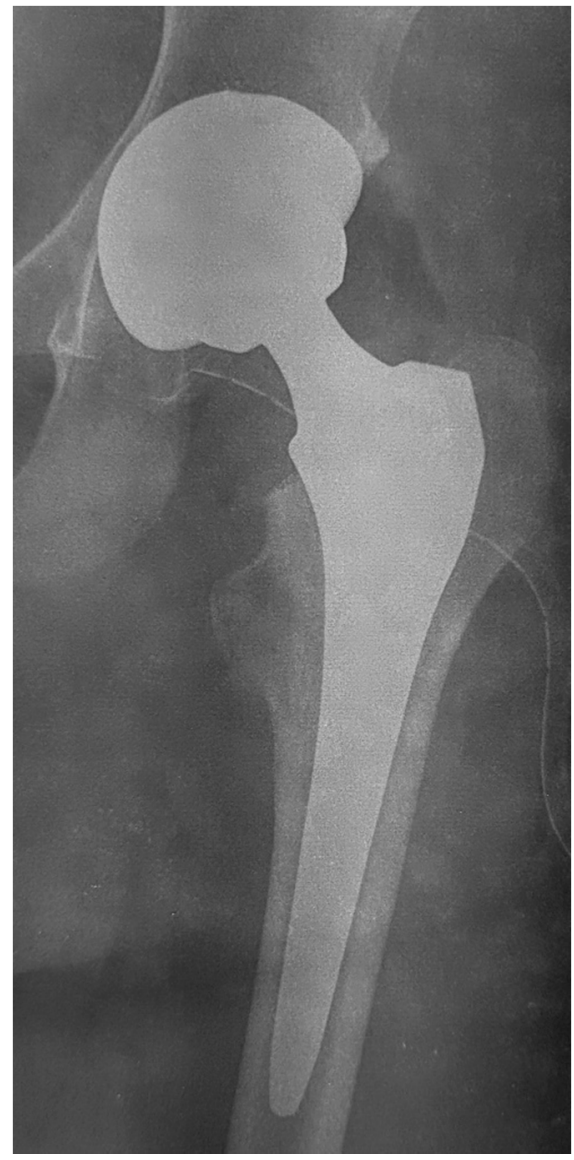

(d)

Figure 1. Female, 14 years old, osteonecrosis of the femoral head in her left hip: preoperative radiological features in $\mathrm{AP}(\mathbf{a})$, axial view (b) and magnetic resonance imaging (c). Postoperative AP X-ray (d) of THA with a $32 \mathrm{~mm}$ AMC-on-AMC coupling. 


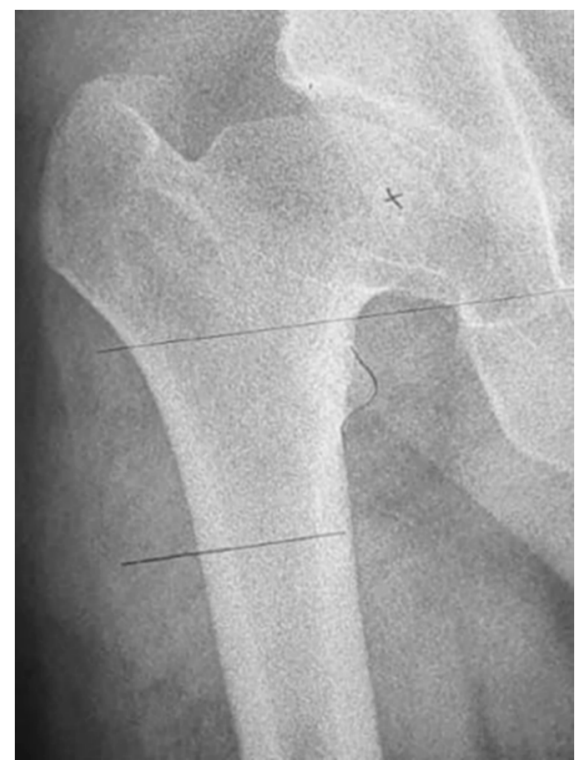

(a)

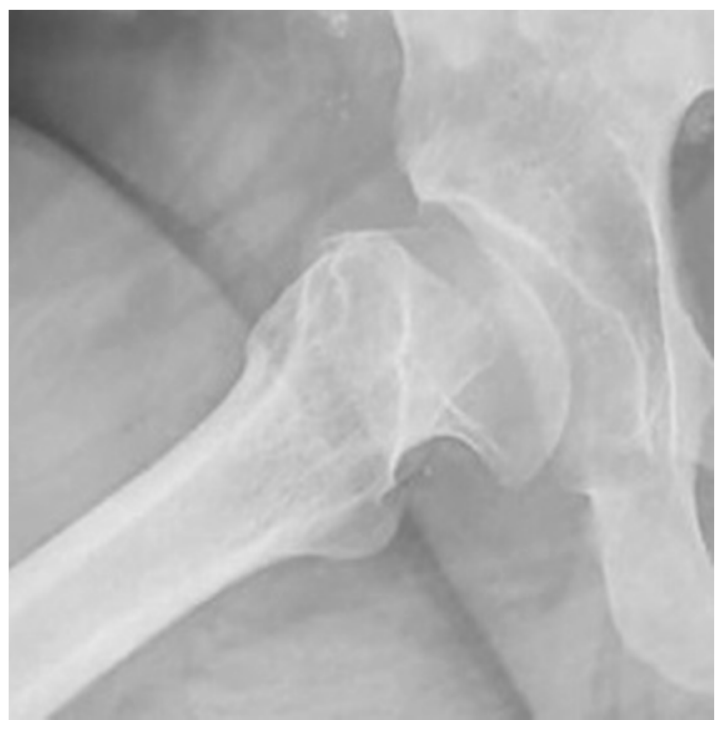

(b)

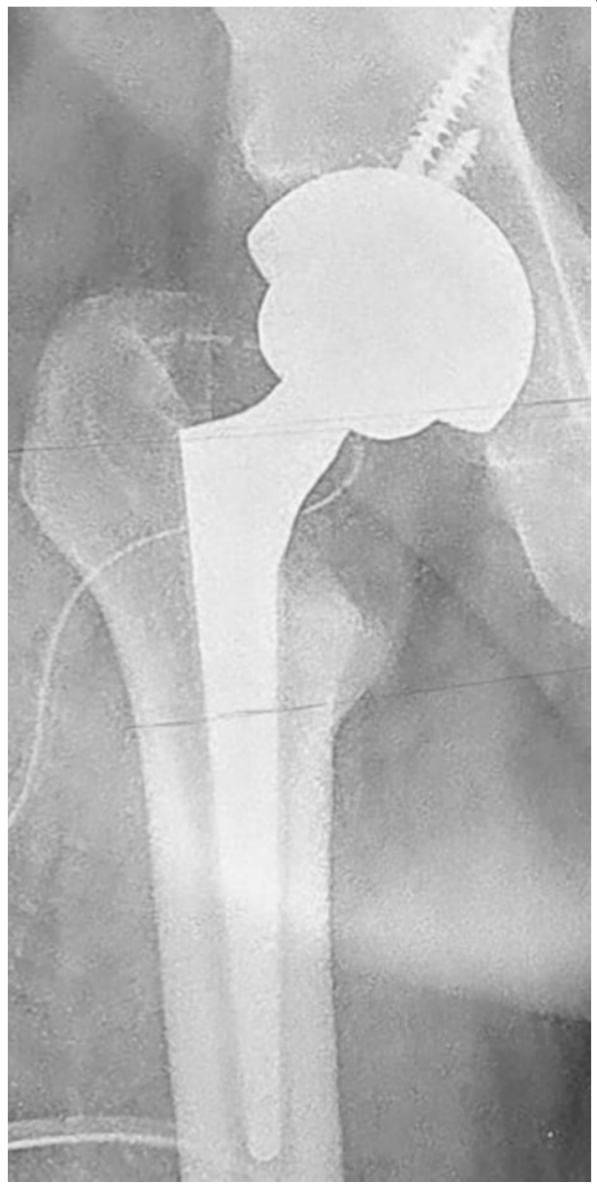

(c)

Figure 2. Male, 55 years old, right hip osteoarthritis secondary to development dysplasia: preoperative AP and axial radiographs (a,b), and postoperative X-ray (c) of the AMC-on-AMC THA using screws for implementation of cup fixation and a conical stem below it.

\subsection{Alumina-on-Alumina Total Hip Replacement for Femoral Neck Fracture}

Because internal fixation has a significantly greater failure probability, resulting in more pain for these patients, primary arthroplasty stands out as the best option for displaced Garden 3 and 4 femoral neck fractures (FFN). When a THA is performed, the surgeon 
must consider implant dislocation as a possible complication, which is said to be more common after a hip fracture, with the posterior surgical approach, in elderly patients with soft-tissue laxity due to sarcopenia and thus poor muscular strength, and the attempt to regain the full range of motion before the injury [41,42]. Even with heads bigger than 28 and $22.2 \mathrm{~mm}$, the ceramic-on-ceramic connection delivers little friction and wear. We believe that after the use of ceramic-on-ceramic bearings in THA, the risk of dislocations can be influenced because, while the risk of fracture should be higher, it will actually be lower after use of heads larger than $28 \mathrm{~mm}$, as in this series: the prevalence of fibrotic response in the tissues surrounding an implant with a CoC articulation may provide a thicker and more resistant capsule in the long term. The periprosthetic retroacetabular bone should not be regarded as a source of stress shielding: the titanium shell is thought to function as a shock absorber between the high stiffness of the alumina and the likely porotic bone, addressing the problem of socket fixation described when a cup of bulky alumina was cemented into the acetabulum [36]. In Bystrom $S$ et al. [42], the femoral head size was shown to be a significant risk factor for prosthesis luxation in a retrospective study of 42,987 primary operations: $22 \mathrm{~mm}$ heads performed as well as or better than $28 \mathrm{~mm}$ heads, while $28 \mathrm{~mm}$ heads led to revision four times more often than $32 \mathrm{~mm}$ heads. According to the Norwegian Arthroplasty Register, femoral head size is a risk factor for total hip luxation, with $28 \mathrm{~mm}$ heads leading to revision substantially more frequently than $32 \mathrm{~mm}$ heads, and $26 \mathrm{~mm}$ heads leading to revision significantly more frequently than $30 \mathrm{~mm}$ heads. The preoperative diagnosis, i.e., an FFN, was also a significant determinant in the luxation revision rate.

In Figure 3, the case of a young man who suffered an FFN after a traffic accident (fall from an electric scooter) is documented: a THA with $36 \mathrm{~mm}$ AMC-on-AMC articulation was implanted.

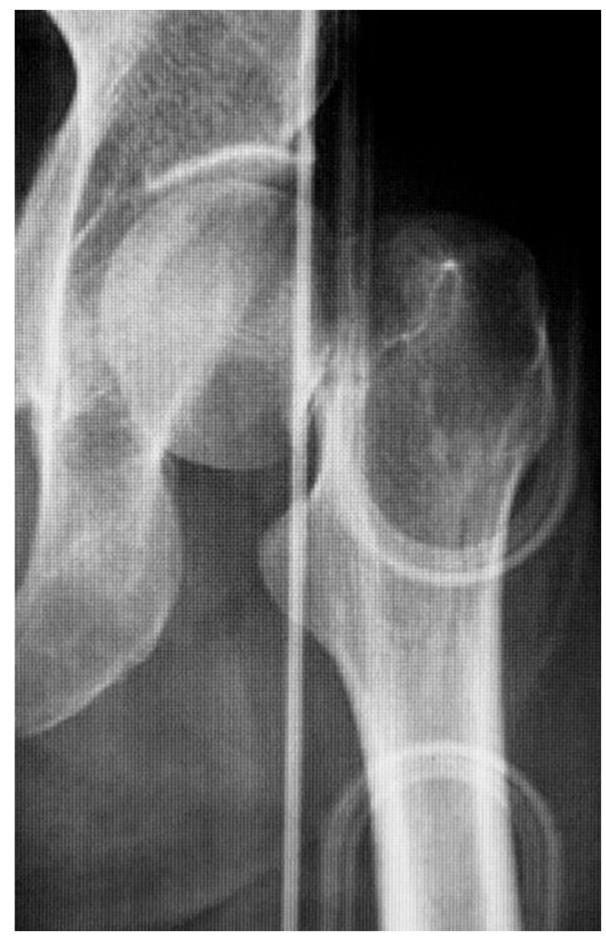

(a)

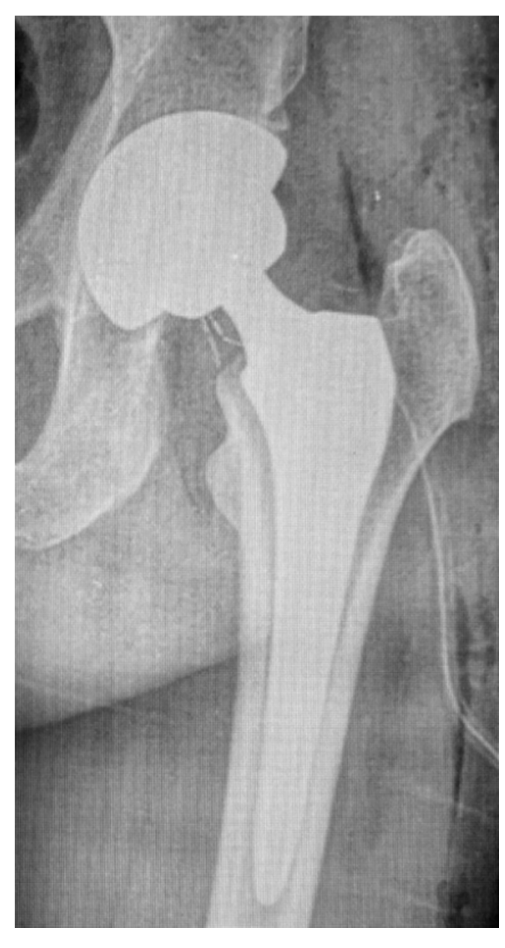

(b)

Figure 3. Male, 42 years old, displaced fracture of his left femoral neck: preoperative AP X-ray of the involved hip (a), and immediate postoperative X-ray (b) of the AMC-on-AMC THA with a $36 \mathrm{~mm}$ head and a stem with a modular neck. 


\section{Conclusions}

Surgeries of joint arthroplasties are among the most successful operations in the entirety of medicine. Since the early 1960s, hip replacement surgical techniques and technology improvements have increased the effectiveness of this procedure. Because the range of motion grows and the jump distance to subluxation and/or dislocation becomes greater, there is significant interest in adopting larger-diameter heads. If we switch to hard-on-hard couplings, we may utilize heads larger than $32 \mathrm{~mm}$ : AMC-on-AMC bearing surfaces are appealing alternative bearing surfaces that remove or substantially minimize the issues associated with PE wear debris. A new low-frictional torque arthroplasty theory can be established owing to their sliding characteristics and better wettability than PE: with ceramic components (inlay and head), due to a lower coefficient of friction, it is possible to enlarge the femoral head diameter without increasing the frictional torque and to grant a wider range of movement that will last because ceramic-ceramic bearings avoid wear. When a PE liner develops wear, the center of rotation migrates centrally and/or cranially, and the deeper the head, the more restricted the range of motion becomes; in fact, late dislocation can be the first clinical sign of wear, with a cumulative risk of firsttime dislocation that is 2 -fold and 3-fold at 10 and 20 years, respectively, when compared to the 1-year follow-up $[14,30-43]$. Breakage of ceramic components is a ceramic-specific issue; we have not seen any fractures in our series.

This may be explained by the better manufacturing process, the exact contact surface geometry, including appropriate clearance, and the greater resistance to fracture when employing heads with a diameter of $32 \mathrm{~mm}$ or bigger. According to Santavirta S [44], the component fracture risk for currently available ceramic goods is essentially non-existent, as demonstrated in clinical trials at 4 and 5 years, even with a $28 \mathrm{~mm}$ head [45,46]. If the diameter is even bigger, more benefits in terms of both strength and function are obtained: in the first three months following surgery, the rate of dislocation was $0.88 \%$ for $36 \mathrm{~mm}$ heads and $4.64 \%$ for $28 \mathrm{~mm}$ heads [47].

Around the world, total hip arthroplasty is becoming more prevalent in younger patients [48]. Ceramic bearing implants for THA surfaces are now extensively utilized across the world to reduce wear debris and aseptic loosening. When utilizing ceramic components, the surgical technique must be precise [49].

Our findings show that AMC-on-AMC couplings provide outstanding outcomes in THA conducted in high-demand patients, with no material-related side effects, no ceramic fracture and no mechanical loosening of implant components. The danger of dislocation should be reduced if the head has a diameter of $32 \mathrm{~mm}$ or more. Overall, we believe AMC-on-AMC to be the bearing of choice for younger and more active patients due to its dependability and longevity.

Author Contributions: Writing—original draft, G.S., A.S., A.V., F.S., M.B. and B.M. All authors have read and agreed to the published version of the manuscript.

Funding: This research received no external funding.

Conflicts of Interest: The authors declare no conflict of interest.

\section{References}

1. Bizot, P.; Nizard, R.; Lerouge, S.; Prudhommeaux, F.; Sedel, L. Ceramic/ceramic total hip arthroplasty. J. Orthop. Sci. 2000, 5, 622-627. [CrossRef] [PubMed]

2. Hannouche, D.; Hamadouche, M.; Nizard, R.; Bizot, P.; Meunier, A.; Sedel, L. Ceramics in total hip replacement. Clin. Orthop. Relat. Res. 2005, 430, 62-71. [CrossRef] [PubMed]

3. Piconi, C.; Streicher, R.M. Forty years of ceramic-on-ceramic THR bearings. Semin. Arthroplast. 2013, 24, 188-192. [CrossRef]

4. Sedel, L. Evolution of alumina-on-alumina implants: A review. Clin. Orthop. Relat. Res. 2000, 379, 48-54. [CrossRef]

5. Lerouge, S.; Yahia Sedel, L. Alumina ceramic in total joint replacement. In Hip Surgery; Martin Dunitz Ltd.: London, UK, 1998; pp. $31-40$.

6. Masson, B. Emergence of the alumina matrix composite in total hip arthroplasty. Int. Orthop. 2007, 33, 359-363. [CrossRef] [PubMed] 
7. Kuntz, M.; Usbeck, S.; Pandorf, T.; Heros, R. Tribology in Total Hip Arthroplasty; Springer: Heidelberg, Germany, 2011 ; pp. 25-40.

8. Kim, Y.H.; Park, J.W.; Kim, J.S. Long-term results of third-generation ceramicon- ceramic bearing cementless total hip arthroplasty in young patients. J. Arthroplast. 2016, 31, 2520-2524. [CrossRef] [PubMed]

9. Solarino, G.; Zagra, L.; Piazzolla, A.; Morizio, A.; Vicenti, G.; Moretti, B. Results of 200 Consecutive Ceramic-on-Ceramic Cementless Hip Arthroplasties in Patients Up To 50 Years of Age: A 5-24 Years of Follow-Up Study. J. Arthroplast. 2019, 34, S232-S237. [CrossRef] [PubMed]

10. Kang, B.-J.; Ha, Y.-C.; Ham, D.-W.; Hwang, S.-C.; Lee, Y.-K.; Koo, K.-H. Third-Generation Alumina-on-Alumina Total Hip Arthroplasty: 14 to 16-Year Follow-Up Study. J. Arthroplast. 2015, 30, 411-415. [CrossRef]

11. Solarino, G.; Piazzolla, A.; Notarnicola, A.; Moretti, L.; Tafuri, S.; De Giorgi, S.; Moretti, B. Long-term results of 32-mm alumina-on-alumina THA for avascular necrosis of the femoral head. J. Orthop. Traumatol. 2012, 13, 21-27. [CrossRef]

12. Engh, C.A.; Stepniewski, A.S.; Ginn, S.D.; Beykirch, S.E.; Sychterz-Terefenko, C.J.; Hopper, R.H. A Randomized Prospective Evaluation of Outcomes After Total Hip Arthroplasty Using Cross-linked Marathon and Non-cross-linked Enduron Polyethylene Liners. J. Arthroplast. 2006, 21, 17-25. [CrossRef]

13. Kim, Y.-H.; Kim, J.-S.; Park, J.-W.; Joo, J.-H. Contemporary total hip arthroplasty with and without cement in patients with oste-onecrosis of the femoral head. A concise follow-up, at a minimum of seventeen years of a previous report. J. Bone Jt. Surg. 2011, 93, 1806-1810. [CrossRef] [PubMed]

14. Kim, Y.-H.; Kim, J.-S.; Park, J.-W.; Joo, J.-H. Periacetabular Osteolysis is the Problem in Contemporary Total Hip Arthroplasty in Young Patients. J. Arthroplast. 2012, 27, 74-81. [CrossRef] [PubMed]

15. Kim, Y.-H.; Park, J.-W.; Kim, J.-S. Alumina Delta-on-Highly Crosslinked-Remelted Polyethylene Bearing in Cementless Total Hip Arthroplasty in Patients Younger than 50 Years. J. Arthroplast. 2016, 31, 2800-2804. [CrossRef] [PubMed]

16. Solarino, G.; Abate, A.; Morizio, A.; Vicenti, G.; Moretti, B. Should we use ceramic-on-ceramic coupling with large head in total hip arthroplasty done for displaced femoral neck fracture? Semin. Arthroplast. 2013, 24, 255-260. [CrossRef]

17. Savarino, L.; Padovani, G.; Ferretti, M.; Greco, M.; Cenni, E.; Perrone, G.; Greco, F.; Baldini, N.; Giunti, A. Serum ion levels after ceramic-on-ceramic and metal-on-metal total hip arthroplasty: 8-year minimum follow-up. J. Orthop. Res. 2008, 26, 1569-1576. [CrossRef]

18. Macdonald, N.; Bankes, M. Ceramic on ceramic hip prostheses: A review of past and modern materials. Arch. Orthop. Trauma Surg. 2014, 134, 1325-1333. [CrossRef]

19. Sentuerk, U.; von Roth, P.; Perka, C. Ceramic on ceramic arthroplasty of the hip: New materials confirm appropriate use in young patients. Bone Jt. J. 2016, 98-B, 14-17. [CrossRef]

20. Howard, D.P.; Wall, P.; Fernandez, M.A.; Parsons, H.; Howard, P.W. Ceramic-on-ceramic bearing fractures in total hip arthroplasty. An analysis of data from the National Joint Registry. Bone Jt. J. 2017, 99, 1012-1019. [CrossRef]

21. Yoon, B.-H.; Park, J.-W.; Cha, Y.-H.; Won, S.-H.; Lee, Y.-K.; Koo, K.-H. Incidence of Ceramic Fracture in Contemporary Ceramicon-Ceramic Total Hip Arthroplasty: A Meta-analysis of Proportions. J. Arthroplast. 2019, 35, 1437-1443.e3. [CrossRef]

22. Buttaro, M.A.; Zanotti, G.; Comba, F.M.; Piccaluga, F. Primary Total Hip Arthroplasty With Fourth-Generation Ceramic-onCeramic: Analysis of Complications in 939 Consecutive Cases Followed for 2-10 Years. J. Arthroplast. 2016, 32, 480-486. [CrossRef]

23. Lee, G.-C.; Kim, R.H. Incidence of Modern Alumina Ceramic and Alumina Matrix Composite Femoral Head Failures in Nearly 6 Million Hip Implants. J. Arthroplast. 2016, 32, 546-551. [CrossRef] [PubMed]

24. Tsikandylakis, G.; Overgaard, S.; Zagra, L.; Kärrholm, J. Global diversity in bearings in primary THA. EFORT Open Rev. 2020, 5, 763-775. [CrossRef]

25. Zagra, L.; Gallazzi, E. Bearing surfaces in primary total hip arthroplasty. EFORT Open Rev. 2018, 3, 217-224. [CrossRef]

26. Zustin, J.; Sauter, G.; Morlock, M.M.; Ruther, W.; Amling, M. Association of osteonecrosis and failure of hip resurfacing arthro-plasty. Clin. Orthop. Relat. Res. 2010, 468, 756-761. [CrossRef]

27. Kannan, A.; Malhotra, R. Letter to the Editor: Association of Osteonecrosis and Failure of Hip Resurfacing Arthroplasty. Clin. Orthop. Relat. Res. 2010, 468, 902-903. [CrossRef]

28. Park, Y.S.; Moon, Y.W.; Lim, S.J.; Yang, J.M.; Ahn, G.; Choi, Y.L. Early osteolysis following second-generation metal-on-metal hip re-placement. J. Bone Jt. Surg. 2005, 87, 1515-1521.

29. Ortiguera, C.J.; Pulliam, I.T.; Cabanela, M.E. Total hip arthroplasty for osteonecrosis: Matched-pair analysis of 188 hips with long-term follow-up. J. Arthroplast. 1999, 14, 21-28. [CrossRef]

30. Berry, D.J.; Harmsen, W.S.; Cabanela, M.E.; Morrey, B.F. Twenty-five-year survivorship of two thousand consecutive primary Charnley total hip replacements: Factors affecting survivorship of acetabular and femoral components. J. Bone Jt. Surg. 2002, 84, 171-177. [CrossRef] [PubMed]

31. Hernigou, P.; Auregan, J.C.; Bastard, C.; Housset, V.; Lachaniette, C.-H.F.; Dubory, A. Higher prevalence of periprosthetic fractures with ceramic on polyethylene hip bearing compared with ceramic on ceramic on the contralateral side: A forty year experience with hip osteonecrosis. Int. Orthop. 2018, 42, 1457-1461. [CrossRef]

32. Geesink, R. Prevention and treatment of recurrent dislocation after total hip arthroplasty. Eur. Instr. Course Lect. 2005, 7, 127-142.

33. Solarino, G.; Moretti, B. Letter to the Editor on "Eighteen-Year Follow-Up Study of 2 Alternative Bearing Surfaces Used in Total Hip Arthroplasty in the Same Young Patients". J. Arthroplast. 2020, 35, 1956-1957. [CrossRef]

34. Learmonth, I.; Hussell, J.; Smith, E. Inadequate polyethylene thickness and osteolysis in cementless hip arthroplasty. J. Arthroplast. 1997, 12, 305-309. [CrossRef] 
35. Takahashi, Y.; Tateiwa, T.; Shishido, T.; Masaoka, T.; Kubo, K.; Yamamoto, K. Size and thickness effect on creep behavior in conventional and vitamin E-diffused highly crosslinked polyethylene for total hip arthroplasty. J. Mech. Behav. Biomed. Mater. 2016, 62, 399-406. [CrossRef]

36. Goebel, P.; Kluess, D.; Wieding, J.; Souffrant, R.; Bader, R.; Heyer, H.; Sander, M. The influence of head diameter and wall thickness on deformations of metallic acetabular press-fit cups and UHMWPE liners: A finite element analysis. J. Orthop. Sci. 2013, 18, 264-270. [CrossRef]

37. Li, G.; Peng, Y.; Zhou, C.; Jin, Z.; Bedair, H. The effect of structural parameters of total hip arthroplasty on polyethylene liner wear behavior: A theoretical model analysis. J. Orthop. Res. 2019, 38, 1587-1595. [CrossRef]

38. Solarino, G.; Piazzolla, A.; Mori, C.M.; Moretti, L.; Patella, S.; Notarnicola, A. Alumina-on-alumina total hip replacement for femoral neck fracture in healthy patients. BMC Musculoskelet. Disord. 2011, 12, 32. [CrossRef] [PubMed]

39. Esposito, C.I.; Carroll, K.M.; Sculco, P.; Padgett, D.E.; Jerabek, S.A.; Mayman, D.J. Total Hip Arthroplasty Patients With Fixed Spinopelvic Alignment Are at Higher Risk of Hip Dislocation. J. Arthroplast. 2018, 33, 1449-1454. [CrossRef] [PubMed]

40. DelSole, E.M.; Vigdorchik, J.; Schwarzkopf, R.; Errico, T.; Buckland, A. Total Hip Arthroplasty in the Spinal Deformity Population: Does Degree of Sagittal Deformity Affect Rates of Safe Zone Placement, Instability, or Revision? J. Arthroplast. 2017, 32, 1910-1917. [CrossRef]

41. Hannouche, D.; Zingg, M.; Miozzari, H.; Nizard, R.; Lübbeke, A. Third-generation pure alumina and alumina matrix composites in total hip arthroplasty: What is the evidence? EFORT Open Rev. 2018, 3, 7-14. [CrossRef] [PubMed]

42. Solarino, G.; Vicenti, G.; Piazzolla, A.; Maruccia, F.; Notarnicola, A.; Moretti, B. Total hip arthroplasty for dysplastic coxarthrosis using a cementless Wagner Cone stem. J. Orthop. Traumatol. 2021, 22, 1-7. [CrossRef] [PubMed]

43. Rogmark, C.; Johnell, O. Orthopaedic treatment of displaced femoral neck fractures in elderly patients. Disabil. Rehabil. 2005, 27, 1143-1149. [CrossRef] [PubMed]

44. Bystrom, S.; Espehaug, B.; Furnes, O.; Havelin, L.I. Norwegian Arthroplasty Register Femoral head size is a risk factor for total hip luxation: A study of 42,987 primary hip arthroplasties from the Norwegian Arthroplasty Register. Acta Orthop. Scand. 2003, 74, 514-524. [CrossRef] [PubMed]

45. Berry, D.J.; Von Knoch, M.; Schleck, C.D.; Harmsen, W.S. Effect of femoral head diameter and operative approach on risk of dislocation after primary total hip arthroplasty. J. Bone Jt. Surg. 2005, 87, 2456-2463.

46. Santavirta, S.; Bohler, M.; Harris, W.H.; Konttinen, Y.T.; Lappalainen, R.; Muratoglu, O.; Rieker, C.; Salzer, M. Alternative materials to improve total hip replacement tribology. Acta Orthop. Scand. 2003, 74, 380-388.

47. Bierbaum, B.E.; Nairus, J.; Kuesis, D.; Morrison, J.C.; Ward, D. Ceramic-on-Ceramic Bearings in Total Hip Arthroplasty. Clin. Orthop. Relat. Res. 2002, 405, 158-163. [CrossRef] [PubMed]

48. Yoo, J.J.; Kim, Y.M.; Yoon, K.S.; Koo, K.H.; Song, W.S.; Kim, H.J. Alumina-on-alumina total hip arthroplasty. A five-year minimum fol-low-up study. J. Bone Jt. Surg. 2005, 87, 530-535. [CrossRef]

49. Zagra, L.; Ceroni, R.G.; Corbella, M. THA Ceramic-Ceramic Coupling: The Evaluation of the Dislocation Rate with Bigger Heads. In Bioceramics in Joint Arthroplasty. Ceramics in Orthopaedics; Steinkopff: Heidelberg, Germany, 2004; pp. 163-169. [CrossRef] 